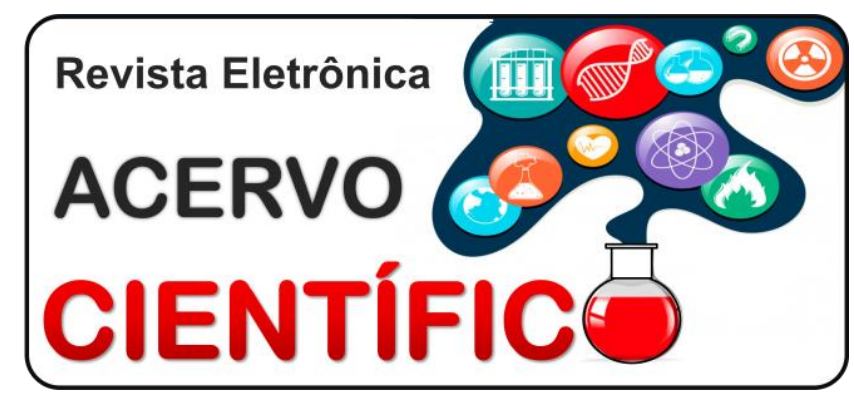

\section{ARTIGO ORIGINAL}

Recebido em: 1/2020

Aceito em: 2/2020

Publicado em: 4/2020

\title{
Prevalência de traço falciforme em doadores de sangue no hemocentro da cidade de Macapá
}

\author{
Falciform trace prevalence in blood donors in the hemocent of Macapá city
}

\section{Prevalencia de rastreo falciform en donantes de sangre en el hemocent de la ciudad de Macapá}

\begin{abstract}
Yasmim Rabelo Pereira ${ }^{1}$, Claude Porcy ${ }^{1}$, Rubens Alex de Oliveira Menezes ${ }^{2 *}$
\end{abstract}
\begin{abstract}
Resumo: Este artigo buscou analisar a prevalência de portadores heterozigoto da hemoglobina $S$ em doadores de sangue no Instituto de Hematologia e Hemoterapia do Estado do Amapá (HEMOAP). Foram analisadas as variáveis etnia e gênero nos períodos de 2016 e 2017, disponibilizadas pelo sistema de gerenciamento do banco de sangue Hemovida do Ministério da Saúde. Os resultados obtidos a partir das análises, nos anos de 2016 e 2017, foram, respectivamente, 1,75\% e 1,3\%; os dados revelaram que a prevalência entre esses doadores portadores é maior no gênero masculino da etnia mestiça. Adicionalmente, os portadores do traço falciforme são assintomáticos, sendo clinicamente e hematológicamente normais e aptos a doação de sangue. Conclui-se que a frequência do traço falciforme no HEMOAP salienta a importância de pôr em prática pesquisas sobre portadores falcêmicos em hemocentros, tendo como finalidade a melhoria da qualidade do sangue transfundido ao receptor e as orientações em saúde para o doador.
\end{abstract}

Palavras-chave: Hemoglobinopatias, Traço falciforme, Doadores de sangue.

Abstract: This article aimed to analyze the prevalence of heterozygous carriers of hemoglobin $S$ in blood donors at the Amapá State Institute of Hematology and Hemotherapy (HEMOAP). The variables ethnicity, gender in the periods of 2016 and 2017, made available by the Hemovida blood bank management system of the Ministry of Health, were analyzed. The results obtained through the analyzes in 2016 and 2017 were $1.75 \%$ and 1 , respectively. $3 \%$, the data revealed that the prevalence among these donor carriers is higher in males of mixed race. Additionally, patients with sickle cell trait are asymptomatic and are clinically and hematologically normal, being able to donate blood. It is concluded that the frequency of sickle cell trait in HEMOAP underlines the importance of carrying out research on sickle cell carriers in blood centers, with the purpose of improving the quality of transfused blood to the recipient and health guidelines for the donor.

Keywords: Hemoglobinopathies, Sickle cell trait, Blood donors.

Resumen: Este artículo tuvo como objetivo analizar la prevalencia de portadores heterocigotos de hemoglobina $S$ en donantes de sangre en el Instituto Estatal de Hematología y Hemoterapia Amapá (HEMOAP). Se analizaron las variables etnicidad, género en los períodos de 2016 y 2017, puestas a disposición por el sistema de gestión del banco de sangre Hemovida del Ministerio de Salud. Los resultados obtenidos a través de los análisis en 2016 y 2017 fueron $1.75 \%$ y 1, respectivamente. 3\%, los datos revelaron que la prevalencia entre estos portadores de donantes es mayor en hombres de raza mixta.

${ }^{1}$ Faculdade Estácio de Macapá, Macapá - AP.

2 Universidade Federal do Amapá (UNIFAP), Macapa - AP. *E-mail: rubens.alex@unifap.br 
Además, los pacientes con el rasgo de células falciformes son asintomáticos, son clínica y hematológicamente normales y pueden donar sangre. Se concluye que la frecuencia del rasgo de células falciformes en HEMOAP subraya la importancia de llevar a cabo investigaciones sobre portadores de células falciformes en los centros de sangre, con el propósito de mejorar la calidad de la sangre transfundida al receptor y las pautas de salud para el donante.

Palabras clave: Hemoglobinopatías, Rasgo de células falciformes, Donantes de sangre.

\section{INTRODUÇÃO}

As hemoglobinopatias são classificadas como as desordens hereditárias que mais afetam as populações mundialmente. No Brasil, a que se destaca com maior prevalência é a hemoglobina $S$, devido ao grande processo de miscigenação, o que gera um grande problema de saúde pública (SILVA JEP e GIOVELLI LL, 2010). A doença falciforme é uma doença hereditária autossômica recessiva, em que ocorre uma mutação na formação da hemoglobina. A globina mutante dispõe de características físico-química diferentes de uma hemoglobina normal, ocasionadas pela mutação que afeta o cromossomo 11 da cadeia beta, na 6 posição do códon, originando uma mutação pontual. Esse defeito genético ocorre devido à troca da base nitrogenada Timina $(T)$ por uma Adenina $(A)$, o que ocasiona a substituição do ácido glutâmico pela valina. Essa alteração origina uma hemoglobina anormal, denominada de hemoglobina S (BRUNETTA DM, et al., 2010).

Em regiões da África, onde a malária se tornou endêmica, foi observado que a população negra, portadora de um gene da hemoglobina $\mathrm{S}(\mathrm{HbS})$, ou seja, um traço falciforme, possuía uma maior resistência à infecção pelo Plasmódium falciparum. Este fator contribuiu para a sobrevivência desta população frente à infecção pela malária $e$, consequentemente, a propagação do gene da hemoglobina $S$ entre seus descendentes. Nesse contexto, acredita-se que o gene da hemoglobina $S$ tenha surgido no Brasil com a entrada de negros escravizados vindos da África durante o processo de colonização do país. (BRASIL, 2009). Dessa forma, é considerada uma das doenças hereditárias mais frequentes no Brasil, ocorrendo prevalentemente entre a população de afrodescendentes e acometendo cerca de $0,1 \%$ a $0,3 \%$, desta população. A doença chamada anemia falciforme se manifesta na forma homozigótica, quando ocorre a presença de dois genes com hemoglobina $S$ recebida de cada genitor, ou mesmo com heterozigose por combinação com outro gene mutante da cadeia beta (FIGUEIREDO AKB, et al., 2014; RAMOS JT, et al., 2017).

O traço falciforme, ou traço sisclêmico, é caracterizado pela forma heterozigota, o indivíduo apresenta apenas um gene da hemoglobina alterada. Esses portadores são assintomáticos, não apresentando alterações hematológicas, no entanto, em determinadas situações, em que esses indivíduos são submetidos a processos prolongados de desoxigenação como longos períodos com anestesia geral, condições extremas de baixa tensão de oxigênio, voo em aviões despressurizados e episódios de acidose, as moléculas desoxigenadas começam a sofrer o processo de polimerização, levando à falcização das hemácias. O eritrócito falcizado acarreta o fenômeno de vasooclusão, que impede o fluxo sanguíneo para os tecidos e órgãos resultando em crises de dores ósseas, torácicas e abdominais intensas e afetando o crescimento, o sistema genitourinário, o sistema cardiopulmonar, o sistema nervoso, a visão, o que causa anormalidades ósseas, esplenomegalia, hepatomegalia, anemia hemolítica, e torna o paciente propenso a infecções e a formação de úlceras na perna (BRASIL, 2009; GIOVELLI LL, et al., 2011).

No traço falciforme, são clinicamente e hematologicamente normais, não havendo alterações em seus achados hematológicos, e com a mesma expectativa de vida de um indivíduo normal, sendo então aptos à doação de sangue. Porém, conforme Brasil (1993), para que se tenha uma melhor qualidade da eficácia terapêutica nas transfusões sanguíneas, foi elaborada no Brasil, em 19 de novembro de 1993, a portaria $n^{0}$ 1.376, para a detecção de hemoglobinopatias em doadores de sangue. Porém, a triagem para hemoglobinas atípicas nos doadores só teve sua obrigatoriedade estabelecida a partir de julho de 2004, de acordo com a Resolução da Diretoria Colegiada da Agência Nacional de Vigilância Sanitária (RDC/ANVISA) $n^{0}$ 153/2004 (BRASIL, 2004). 
Essa resolução teve como importância aumentar a eficácia da qualidade do sangue a ser transfundido, dando ao receptor uma melhor segurança em sua terapia. A identificação da prevalência de portadores de traços falciforme em doadores de sangue é de suma importância, pois perdura, há anos no Brasil, uma alta taxa de portadores do traço, devido ao processo de mistura de raças. Contudo, a chance do encontro de um receptor heterozigoto da hemoglobina $S$ é bem alta, então mostra-se importante a triagem desses portadores (GIOVELLI LL, et al., 2011; RODRIGUES DD, et al., 2017).

O emprego terapêutico de hemocomponentes e hemoderivados é realizado em emergências, com o objetivo de repor a perda sanguínea ou tratar doenças e/ou evitar a progressão de sinais e sintomas. Tais medidas têm por objetivo melhorar o prognóstico do paciente. Atualmente, novas técnicas foram aperfeiçoadas, bem como as regulamentações e legislações em relação ao ciclo do sangue tornaram-se mais exigentes, a fim de garantir a segurança no ato transfusional, tanto para o doador, quanto para 0 receptor (BRASIL, 2004).

Nesse contexto, e considerando as altas taxas de prevalência de indivíduos heterozigoto e homozigoto da doença falciforme, faz-se necessário que haja políticas com aconselhamento genético e orientações educativas para que esses indivíduos e a população tenham conhecimentos sobre o traço falciforme e a anemia falciforme, tendo em vista que os portadores de traço falciforme são potenciais geradores de crianças com a forma homozigoto da doença, ou seja, com anemia falciforme (SOUSA AM e SILVA FRA, 2017).

Esse artigo tem como objetivo analisar a prevalência de portadores heterozigoto da hemoglobina $\mathrm{S}$ em doadores de sangue no Instituto de Hematologia e Hemoterapia do Estado do Amapá.

\section{MÉTODOS}

Trata-se de uma pesquisa exploratória, quantitativa, na qual os dados foram obtidos a partir do sistema de gerenciamento do banco de sangue Hemovida do Ministério da Saúde, disponibilizado pelo Instituto de Hematologia e Hemoterapia do Estado Amapá, autorizado pelo diretor do hemocentro. Os dados fornecidos pelo Instituto referem-se ao período de 2016 a 2017, e são de indivíduos aptos à doação. Estes dados foram organizados em tabelas e planilhas, usando como ferramenta o Microsoft Excel, versão 2010, com cálculos das frequências absolutas e relativas, o que possibilitou a construção de gráficos.

As variáveis analisadas foram: etnia e gênero, referentes aos anos da pesquisa, de todos os doadores heterozigotos para Hemoglobina S. Para o presente artigo foi solicitado à dispensa do consentimento livre $e$ esclarecido, pois o projeto não utilizou de pesquisa com seres humanos e/ou animais, e sim utilização de informações de banco de dados, sendo submetidos ao comitê de ética, para obtenção do protocolo de isenção.

\section{RESULTADOS E DISCUSSÃO}

Os dados analisados no referido estudo, de acordo com a (Tabela 1), no ano 2016, mostraram que, dos 13.305 exames realizados no Instituto, $231(1,75 \%)$ desses doadores foram diagnosticados como portadores do traço falcêmico. No ano de 2017, dos 13.404 exames executados para detecção de indivíduos heterozigotos da hemoglobina S, 176, ou seja, 1,3\% foram diagnosticados.

Tabela 1 - Prevalência de Portadores de HbS em Doadores de Sangue do Instituto de Hematologia e Hemoterapia nos Anos de 2016 e 2017.

\begin{tabular}{cccc}
\hline Período & Total de Exames & Positividade & Porcentagem (\%) \\
\hline 2016 & 13.305 & 231 & $1,75 \%$ \\
2017 & 13.404 & 176 & $1,3 \%$ \\
\hline
\end{tabular}

Fonte: Pereira YR, et al., 2019. 
Os resultados encontrados no hemocentro de Macapá, no que se refere ao percentual de doadores portadores da HbS, aproximam-se dos resultados obtidos em outros estudos, como a uma pesquisa de Moraes KCM e Galioti JB (2010) sobre um estudo genético-populacional a partir de doadores de sangue da cidade São José dos Campos, no qual mostrou-se uma prevalência de 0,43\% desses indivíduos. Bernieri T, et al. (2017), em um estudo na população de doadores do Hemocentro de Passo Fundo RS, verificaram uma prevalência de $0,4 \%$ de traço falciforme entre os doadores. Outro estudo, desta vez realizado por Lidani KCF, et al. (2015), identificou uma prevalência de $0,9 \%$ em doadores em um banco de sangue no munícipio de Curitiba - PR. Estudo realizado por Silva RA, et al. (2016), no departamento de hemoterapia de Rondanópolis - MG, encontrou um percentual de 2,04\% dos doadores portadores de hemoglobina HbS.

Os resultados apresentados, no ano de 2016 e 2017, nos doadores do Hemocentro do Estado do Amapá, se aproximam a esses resultados obtidos em outros Hemocentros do Brasil, o que demostra que a presença de Hemoglobina $S$ em doadores de sangue não é exclusividade do Estado do Amapá, sendo assim encontrada em percentuais variados em populações de doadores de vários Hemocentros do território Nacional. Adicionalmente, a presença de indivíduos portadores da hemoglobina $S$ no Brasil, de acordo com consideráveis estudos, diferenciam-se de uma região para outra (SILVA JEP e GIOVELLI LL, 2010). As associações das distintas origens étnicas, derivadas de países africanos, europeus e asiáticos, repercutiu de certa forma, com a abundante miscigenação da população brasileira (IBGE, 2011). Os resultados atingidos nesse estudo contribuem para o conhecimento dessa alteração dos eritrócitos em nossa população.

Em relação ao gênero dos doadores analisados, a (Figura 1) demonstra que, dos 231 doadores identificados como portadores de traço falciforme, no período de 2016, 152 (66\%) eram do gênero masculino e 79 (34\%) do gênero feminino. No ano 2017, dos 176 doadores positivados para hemoglobina S, 121 eram do gênero masculino, ou seja, 69\% desses indivíduos, e 55 (31\%) do gênero feminino.

Figura 1 - Porcentagem de doadores portadores heterozigotos da hemoglobina $S$ de acordo com gênero nos períodos de 2016 e 2017.

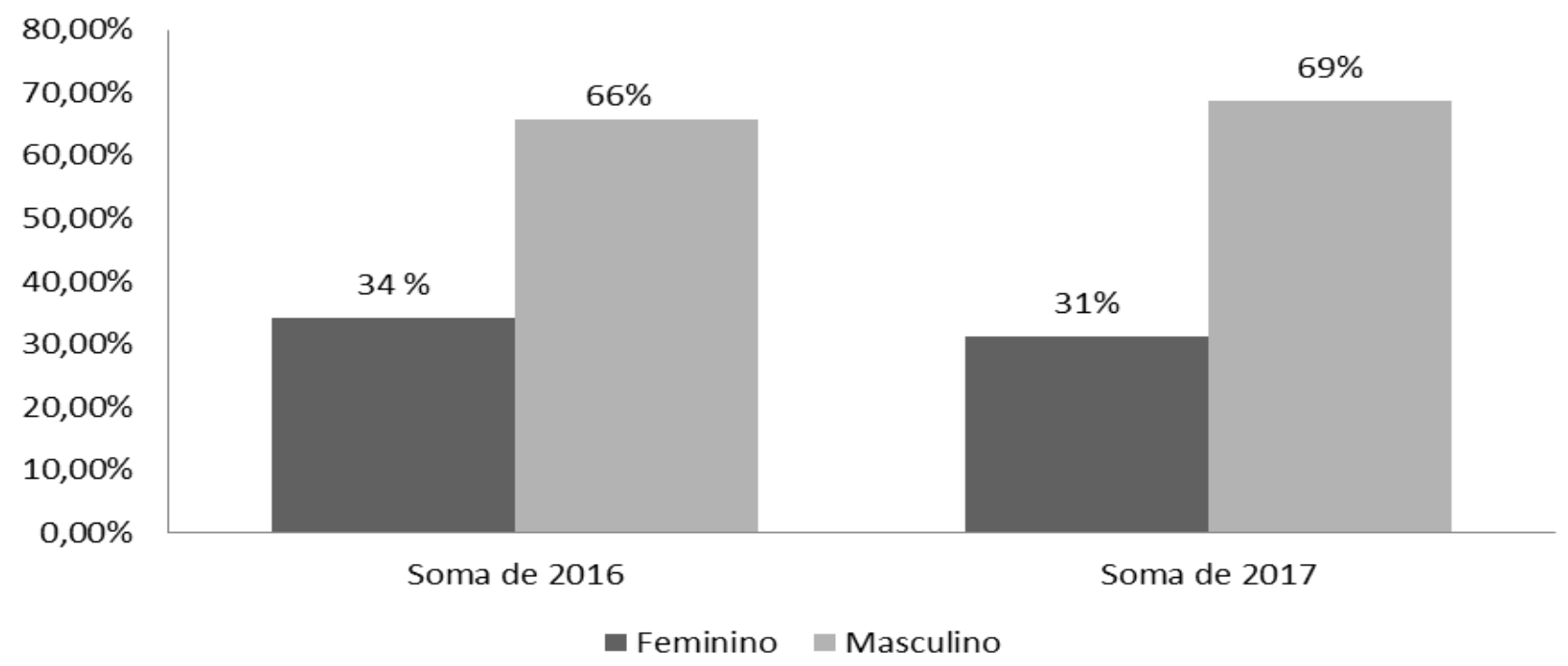

Fonte: Pereira YR, et al., 2019.

No que diz respeito ao gênero dos doadores, os dados do presente artigo corroboram com estudo de Georg AH e Shimauti ELT (2015), provenientes da rede HEMEPAR do estado do Paraná, em que, dos indivíduos doadores identificado como portadores do traço falciforme, o gênero que apresentou uma maior prevalência foi o sexo masculino, com 56,45\%. De forma similar, a pesquisa de Bernieri T, et al. (2017) em doadores do hemocentro do Rio Grande do Sul também encontrou maior prevalência do traço falciforme no 
gênero masculino (60.8\%). De acordo com Antwi-baffour S, et al. (2015), esse predomínio de doadores de sangue do gênero masculino no Brasil tem como uma possível justificativa as condições fisiológicas do gênero feminino como, gravidez e lactação, sendo também a maioria dessas pessoas acometidas por anemia, o que as exclui na triagem.

Outra variável analisada nesta pesquisa foi a relação da etnia dos portadores do traço falciforme. Nesse aspecto, segundo a (Figura 2), no ano de 2016, obteve-se os seguintes resultados: $125(54,11 \%)$ dos doadores declaravam-se mestiços, 81 (35,06\%), negros, e 23(9,96\%), caucasianos. Dos 231 doadores portadores de traço falciforme, $2(0,87)$ não informaram a sua etnia (Figura 2).

Figura 2 - Porcentagens de indivíduos identificados heterozigotos para hemoglobina $\mathrm{S}$ em relação à etnia no ano 2016.

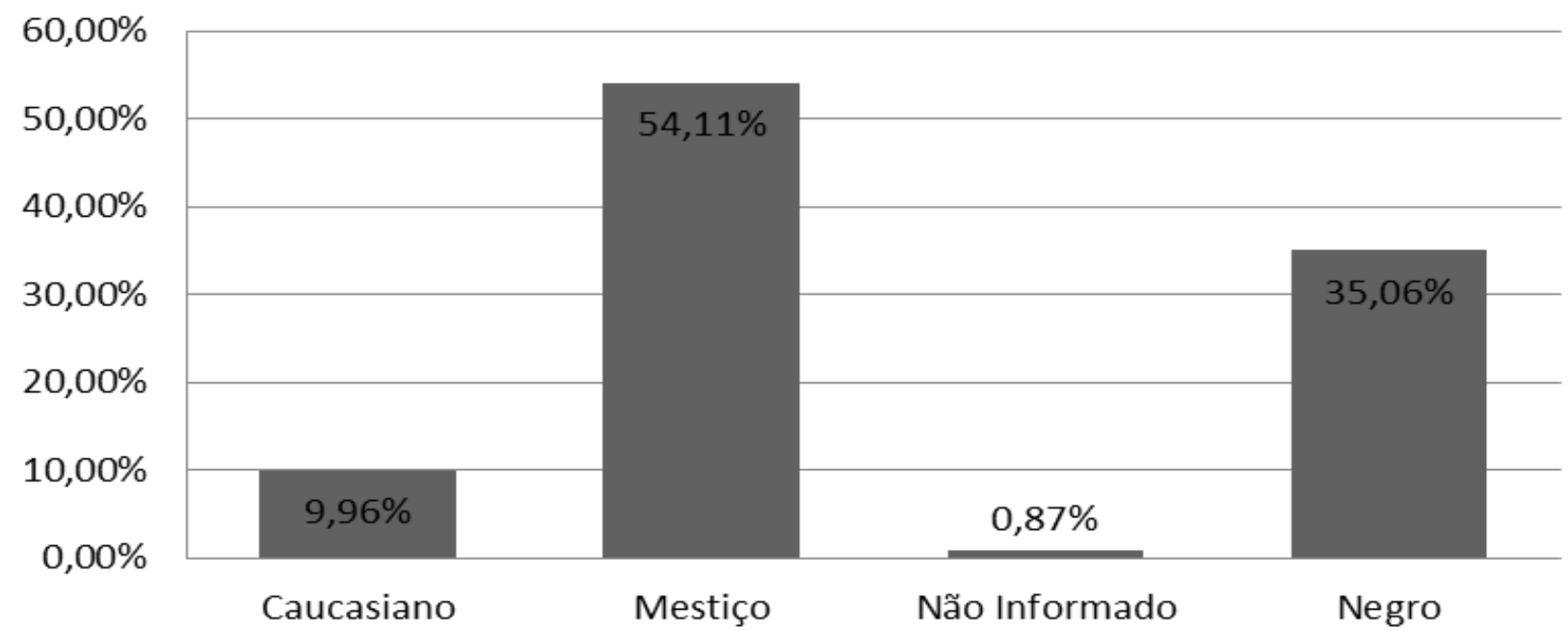

Fonte: Pereira YR, et al., 2019.

Quanto ao ano de 2017, de acordo com a (Figura 3), observa-se que a etnia que mais prevaleceu em relação às demais foi a etnia autorreferida pelos doadores como mestiça $(56,82 \%)$, conforme apresentado na figura abaixo.

Figura 3 - Porcentagens de doadores positivos para hemoglobinopatias do Instituto de Hematologia e Hemoterapia do Estado do Amapá no período de 2017, distribuído por etnia.

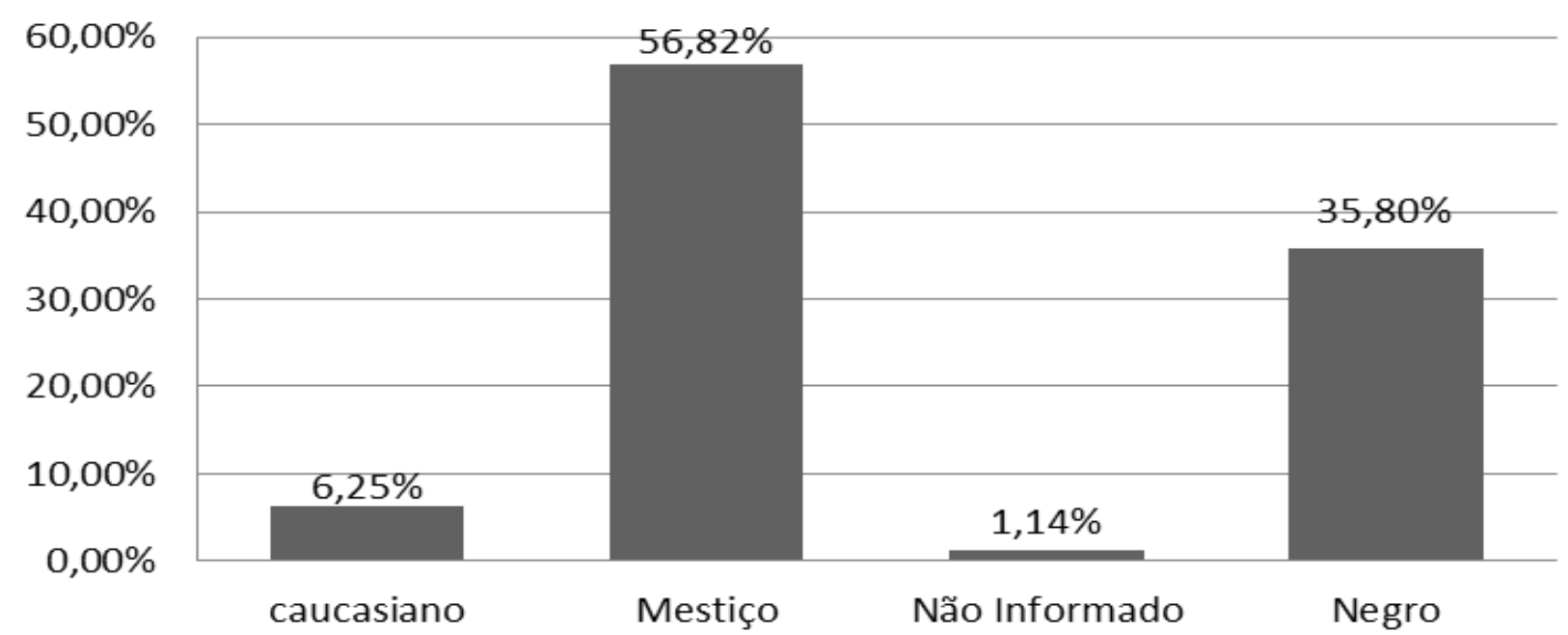

Fonte: Pereira YR, et al., 2019. 
No Brasil, apresenta-se por uma importante heterogeneidade racial, sendo assim a distribuição de hemoglobinas anormais está diretamente ligada às descendências étnicas que colaboraram com a formação da população de cada região. No que diz a respeito à etnia, após a análise desta variável, nos dois períodos da pesquisa, constatou-se que a etnia dos mestiços apresentou uma prevalência significativa em relação às demais, de acordo com o que está exposto nas (Figuras 2 e 3) deste estudo, nas quais observa-se maior predominância nos doadores que se autodeclararam mestiços, seguido de negros, caucasianos e não informados.

Adicionalmente, os estudos sobre prevalência do traço e doença falciformes associados às características étnicas da população têm sido bastante explorados nas pesquisas. No Brasil, diversos estudos demostram a associação entre a ascendência étnica das pessoas com doença falciforme, a cor da pele e a região geográfica em que residem, principalmente em populações residentes em áreas de quilombos, onde a associação entre doença falciforme, composição étnica da população e migração são fatores de importância para entender a presença do traço falciforme no Brasil (DINIZ D, et al., 2009). Importante enfatizar que a expressão do traço falciforme, localização geográfica e especificidades migratórias de cada região determinam a presença do traço e da anemia falciformes.

Em contrapartida, estudos realizados em diferentes hemocentros das diversas regiões do Brasil afrontam o resultado obtido neste estudo, como pode ser observado no trabalho realizado por Valer TSP, et al. (2012), no qual demostrou-se que a etnia que mais prevaleceu em relação as outras foi a negra com $4,55 \%$, enquanto que a mestiça se apresentou com 2,29\% nos doadores do banco de sangue da cidade de Maringá. Já de acordo com Moraes KCM e Galioti JB (2010), em seu estudo realizado em doadores de sangue na cidade de São José dos Campos, $24 \%$ dos portadores do traço se declaram ser da etnia negra, seguido de $20 \%$ da etnia mestiça. Outro estudo que corrobora com a divergência do resultado adquirido no corpo desse artigo foi o de Bernieri T, et al. (2017), que mostrou que entre os indivíduos doadores portadores de traço falciforme do hemocentro de Passo Fundo, a etnia que mais prevaleceu foi a branca, explicação que se deve pelo fato da cidade ser colonizada por imigrantes italianos e alemães. A prevalência entre as etnias negras e pardas está diretamente ligada às descendências históricas das regiões em que esses estudos foram realizados.

No Brasil, existe um elevado número de populações com heterogeneidade étnica e, com isso, a prevalência do traço falciforme e da anemia falciforme. Assim, a chance de se deparar com um receptor de sangue com essa característica é alta, o que minimizaria a eficácia da transfusão caso este indivíduo receba concentrado de hemácias provenientes de algum doador positivo para a presença de $\mathrm{Hb} \mathrm{S}$. Portanto, com a investigação de hemoglobinas variantes nos doadores, o receptor será resguardado ao recebimento de hemácias anormais que podem tornar a transfusão ineficaz (SILVA RA, et al., 2016).

Adicionalmente, é de grande relevância a realização da triagem dos portadores de hemoglobinas alteradas nos bancos de sangue, beneficiando simultaneamente o doador e o receptor. Esta pesquisa enfatiza a importância do aconselhamento genético para os indivíduos que apresentam a forma heterozigota da anemia falciforme - o traço falcêmico - e ressalta a necessidade e importância de implantação de programas de diagnóstico precoce e de orientação genética, social e psicológica para os indivíduos que possuem a doença e o traço falciformes (ANTWI-BAFFOUR S, et al., 2015; BRASIL, 2004).

\section{CONCLUSÃO}

Esta pesquisa mostrou que a existência do traço falciforme entre os doadores do Instituto de Hematologia e Hemoterapia do Estado do Amapá, no período estudado, aproxima-se dos demais estudos, nos quais observa-se uma baixa prevalência de portadores heterozigotos $\mathrm{HbS}$ na população de brancos, com predomínio nos homens. Portanto, vale salientar a necessidade de pôr em prática pesquisas de portadores falcêmicos em hemocentros, tendo como objetivo a melhoria da qualidade do sangue transfundido ao receptor e as orientações em saúde para o doador, que pode desconhecer sua situação. Ainda, considerando a miscigenação da população e a alta prevalência do traço falcêmico em algumas regiões do país, consideramos fundamental a realização de mais estudos epidemiológicos nessas áreas. 


\section{REFERÊNCIAS}

1. ANTWI-BAFFOUR $S$, et al. Prevalência da característica da hemoglobina $S$ no sangue doadores: um estudo transversal. Notas Res do BMC. 2015; 8 (583): 2-6.

2. BERNIERI T, et al. Prevalência de hemoglobina $\mathrm{S}$ em doadores de sangue do hemocentro de Passo Fundo, Rio Grande do Sul, Brasil. Rev. Bras. Pesq. Saúde, 2017; 19(4): 104-108.

3. BRASIL. Ministério da Saúde. Gabinete do Ministro. Portaria no 1.376, de 19 de novembro de 1993. Aprova as alterações da Portaria no 721/GM, de 9/8/89, que aprova as normas técnicas para coleta, processamento e transfusão de sangue, componentes e derivados, e dá outras providências. Brasília, Diário Oficial da União, p. 18404, 2 de dezembro de 1993.

4. BRASIL. Ministério da Saúde. Gabinete do Ministro. Portaria no 153, de 14 de junho de 2004. Aprova as normas técnicas para coleta, processamento e transfusão de sangue, componentes e derivados e dá outras providências. Brasília, DF, 2004.

5. BRASIL. Ministério da Saúde Secretaria de Atenção à Saúde. Departamento de atenção especializado; Manual de Educação em Saúde, linha de cuidado em Doença Falciforme Brasília. v. 2. 2009.

6. BRUNETTA DM, et al. Manejo das complicações agudas da doença falciforme. Revista de Medicina online, 2010; 43: $231-7$.

7. DINIZ D, et al. Prevalência do traço e da anemia falciforme em recém-nascidos do Distrito Federal, Brasil, 2004 a 2006. Cad. Saúde Pública, 2009; 25(1):188-194.

8. FIGUEIREDO AKB, et al. Anemia Falciforme: Abordagem diagnóstica laboratorial. Rev. Ciênc. Saúde Nova Esperança, 2014; 12(1): 96-103.

9. GEORG, AH, SHIMAUTI ELT. Estudo da prevalência de hemoglobinopatias em doações de sangue do centro de hemoterapia e hematologia do Paraná. Hemoterapia: Artigos científicos de conclusão de curso de pós-graduação lato sensu em Hemoterapia. Curitiba, 2015.

10. GIOVELLI LL, et al. Estudo comparativo entre metodologias de triagem para detecção de hemoglobina $S$ em bancos de sangue. Bras Patol Med Lab. 2011; 47(2): 137-140.

11. INSTITUTO BRASILEIRO DE GEOGRAFIA E ESTATÍSTICA (IBGE). Resultados Preliminares do universo do Censo Demográfico 2010. Rio de Janeiro 2011.

12. LIDANI KCF, et al. Relationship between the prevalence of hemoglobin and the ethnic background of blood donors in Paraná State. J Bras Patol Med Lab. 2015; 51(4):212-7.

13. MORAES KCM, GALIOTI JB. A doença falciforme: um estudo genético-populacional a partir de doadores de sangue em São José dos Campos, São Paulo, Brasil. Rev. Bras. Hematol. Hemoter. 2010; 32(4): 286-290.

14. RAMOS JT, et al. Mortalidade Infantil por Doença Falciforme na Bahia: Um Estudo Epidemiológico. Rev. Saúde Col. 2017; 7(3): 36-39.

15. RODRIGUES DD, et al. Recorte bibliográfico da prevalência e diagnóstico da Anemia Falciforme. Rev Pat Tocantins, 2017: 4(1): 23-38.

16. SILVA JEP, GIOVELLI LL. Traço falciforme: uma visão para os centros de hemoterapia. Revista Saúde, 2010; 36(1): 23-28.

17. SILVA RA, et al. Avaliação genético-populacional da doença falciforme a partir de doadores de sangue em Rondonópolis, Mato Grosso, Brasil. Biodiversidade, 2016; 15(3): 111-120.

18. SOARES LF, et al. Prevalência das hemoglobinas $\mathrm{S}$ e $\mathrm{C}$ em heterozigose em duas comunidades de povos de Terreiros na cidade de Teresina, Piauí. Rev Ciênc Farm Básica, 2015; 36(1): 91-95.

19. SOUSA AM, SILVA FRA. Traço falciforme no Brasil: revisão da literatura e proposta de atenção primária. Rev Med UFC. $2017 ; 57(2): 37-43$.

20. VALER TSP, et al. Hemoglobinopatias: Prevalência em doadores de sangue. Revista Saúde e Pesquisa. $2012 ; 5$ : 27-34. 